\title{
Entero-adherent Escherichia coli is an important diarrhoeagenic agent in infants aged below 6 months in Calcutta, India
}

\author{
A. R. GHOSH, G. B. NAIR, T. N. NAIK, MOUSUMI PAUL, S. C. PAL and D. SEN*
}

National Institute of Cholera and Enteric Diseases, P-33, CIT Scheme XM, Beliaghata, Calcutta-700 010, India

\begin{abstract}
Summary. Escherichia coli adherent to HEp-2 and HeLa cells were isolated from the faeces of $43(19.7 \%)$ of 218 hospitalised infants aged below 6 months with acute diarrhoea. No conventional virulence factors, including enterotoxin production-heat-labile (LT) or heatstable (ST), the verotoxin (VT) or shiga-like toxin (SLT)-or the invasive phenotype (determined by the Sereny test) could be detected among these isolates. Out of the 43 isolates, $16(37 \cdot 2 \%)$ were of the known enteropathogenic $\mathrm{O}: \mathrm{K}$ serogroups - enteropathogenic $E$. coli (EPEC). The remaining $27(62.8 \%)$ isolates showed different types of adherence to HEp-2 and HeLa cells which was diffuse $(40.7 \%)$, localised $(37.0 \%)$, or both $(22.3 \%)$; they were identified as entero-adherent $E$. coli (EAEC). The EAEC isolates adhered to HEp-2 and HeLa cells in the presence of mannose, lactose, fucose, galactose, and fetuin, indicating that adhesion was not specific for these sugars or glycoprotein. Haemagglutination and the salt aggregation test (SAT) did not correlate with patterns of adherence. The results of this study indicate that LA-EAEC is an important aetiological agent of acute diarrhoea in infants aged below 6 months in Calcutta.
\end{abstract}

\section{Introduction}

Depending on the pattern of adherence, Escherichia coli of non-enteropathogenic serogroups that adhere to HEp-2 or HeLa tissue cells in culture have been referred to as entero-adherent $E$. coli $\left(\right.$ EAEC) ${ }^{1}$ or entero-adherent aggregative $E$. coli (EA-AggEC). ${ }^{2}$ Strains of EAEC that exhibit localised adherence (LA) form clusters or microcolonies of bacteria on the HEp2 cell surface; strains that exhibit diffuse adherence (DA) are found evenly distributed over the surfaces of the cells. ${ }^{3}$ In contrast, strains of $E$. coli classified as EA-AggEC adhere on the surfaces of the cultured cells as well as on the glass slide free from cells, assuming a characteristic stacked-brick pattern. ${ }^{2,4,5}$

The non-EPEC adherent groups of $E$. coli are emerging, and have been incriminated epidemiologically, as one of the conspicuous aetiological agents of diarrhoea amongst travellers ${ }^{1}$ and children. ${ }^{2,6-10}$ However, considering the controversy and debate on the aetiological role of EAEC and EA-AggEC and on the methodologies being used for the adherence test, the role of both the groups in causing diarrhoea in man needs to be investigated in greater detail. ${ }^{11}$ The present study was initiated to determine the impor-

Received 6 Dec. 1990; revised version accepted 24 June 1991. * Correspondence should be sent to Dr D. Sen. tance of adherent non-EPEC isolates of $E$. coli in causing acute diarrhoea in infants aged below 6 months in Calcutta.

\section{Materials and methods}

\section{Faecal specimens}

During the period from April 1986 to March 1988, 218 infants with diarrhoea aged below 6 months admitted to the Dr B. C. Roy Memorial Hospital for Children, Calcutta, Monday-Saturday, 0900-1300 h, were included in the study; 102 infants matched for age, gender and socio-economic status attending the out-patient department of the same hospital for immunisation or for reasons other than gastrointestinal illness, were also investigated concurrently and served as controls.

Faecal samples of the study population were examined for bacterial enteropathogens by standard procedures. ${ }^{12}$ Stool samples were examined by microscopy for trophozoites and cysts of Entamoeba histolytica and Giardia lamblia. Oocysts of Cryptosporidium spp. were also sought by the acid-fast Zeil-Neelsen method. ${ }^{13}$ All samples were examined for the presence of rotavirus antigen by the enzyme linked immunosorbent assay (ELISA) ${ }^{14}$ (table I). 
Detection of toxin( $s$ ) and invasiveness in E. coli isolates

For each specimen examined, three characteristic lactose-fermenting colonies from the primary MacConkey plates, identified as $E$. coli by conventional procedures, ${ }^{12}$ were screened for production of heatlabile toxin (LT) by the modified Elek test ${ }^{15}$ and the $\mathrm{GM}_{1}$-ELISA, ${ }^{16}$ for heat-stable toxin (ST) by the suckling mouse assay, ${ }^{17}$ and for Vero toxin (VT) (shiga-like toxin; SLT) by the Vero cell assay ${ }^{18}$ and by the recently developed sensitive VT1/VT2 beadELISA technique. ${ }^{19}$ The strains were also tested for the invasive phenotype by the guinea-pig keratoconjunctivitis model. ${ }^{20}$

\section{Tests for adherence}

Strains of $E$. coli which were non-invasive and nonproducers of LT, ST or VT were tested for adherence to the HEp-2 and HeLa cultured cells by the procedure detailed by Cravioto et al. ${ }^{21}$ Briefly, $20 \mu \mathrm{l}\left(\mathrm{c} .10^{7} \mathrm{cfu}\right)$ of bacterial culture, grown overnight in tryptic soy broth with agitation at $37^{\circ} \mathrm{C}$, was added to tissueculture cells grown to $c .60 \%$ confluence on plastic petri dishes containing sterile glass cover slips. The inoculated tissue culture cells were incubated for $3 \mathrm{~h}$ at $37^{\circ} \mathrm{C}$ in $\mathrm{CO}_{2} 5 \%$ in air. Adherence to mammalian cells was tested in the presence or absence of mannose, lactose, fucose or galactose (each at $1 \%$ ) and the glycoprotein fetuin $(0 \cdot 1 \%)$. After incubation, the cover slips were washed with PBS (pH 7.2), dried in air, fixed in methanol for $2 \mathrm{~min}$, stained with Giemsa $1 \%$ in methanol for $1 \mathrm{~min}$ and mounted on microscope slides with Canada balsam. Adherence of $E$. coli to mammalian cells was examined under bright-field illumination. The pattern of bacterial adherence to HEp- 2 and HeLa cells was evaluated according to the description of Nataro et al. ${ }^{2}$ Although three isolates of $E$. coli were picked from each case, if one isolate from the case exhibited adherence, the other two isolates were not tested.

\section{Tests for EPEC serogroups, hydrophobicity and haemagglutination}

E. coli strains that were adherent to HEp-2 and HeLa cells were tested for agglutination with commercially available EPEC $(\mathrm{O}: \mathrm{K})$ antisera (Wellcome Reagents). The entero-adherent non-enteropathogenic $E$. coli isolates were tested for hydrophobicity by a salt aggregation test (SAT) ${ }^{22}$ with various molar concentrations of ammonium sulphate and for haemagglutination (mannose-sensitive and mannose-resistant) ${ }^{23}$ with $3 \%$ suspensions of erythrocytes of human group $\mathrm{A}$, bovine, chicken or guinea-pig.

\section{Results}

Bacterial, viral and parasitic enteropathogens detected in the faeces of $167(76.6 \%)$ infants with diarrhoea either singly $(56.4 \%)$ or in association with other enteropathogens $(20.2 \%)$ are shown in table I. In contrast, the frequency of detection of enteropathogens was $16.7 \%$ in the healthy controls. The three groups of diarrhoeagenic E. coli-EPEC, ETEC and EAEC - together accounted for $57.3 \%$ of the cases and were the major aetiologic agents; 81 of the

Table I. Prevalence of different enteropathogens among acute diarrhoeic and non-diarrhoeic infants aged below 6 months in Calcutta

\begin{tabular}{lcc}
\hline & \multicolumn{2}{c}{ Number $(\%)$ of isolates from } \\
\cline { 2 - 3 } Enteropathogen(s) detected & cases $(218)$ & controls (102) \\
& $123(56 \cdot 4)$ & $14(13 \cdot 8)$ \\
& $81(37 \cdot 2)$ & $9(8 \cdot 9)$ \\
Sole pathogen & $46(21 \cdot 1)$ & $7(6 \cdot 9)$ \\
Diarrhoeagnic E. coli & & \\
Enteropathogenic E. coli & $17(7 \cdot 8)$ & 0 \\
(EPEC) & & \\
Enterotoxigenic E. coli & $18(8 \cdot 3)$ & $2(1 \cdot 9)$ \\
(ETEC) & & \\
Entero-adherent E. coli & $10(4 \cdot 6)$ & $\mathrm{NT}$ \\
(EAEC) & $7(3 \cdot 2)$ & $1(1 \cdot 0)$ \\
Rotavirus & $7(3 \cdot 2)$ & $1(1 \cdot 0)$ \\
Salmonella typhimurium & $7(3 \cdot 2)$ & $3(2 \cdot 9)$ \\
Campylobacter jejuni & $4(1 \cdot 9)$ & 0 \\
Aeromonas hydrophila & $6(2 \cdot 7)$ & 0 \\
Shigella spp. & $1(0 \cdot 5)$ & 0 \\
Cryptosporidium spp. & $44(20 \cdot 2)$ & $3(2 \cdot 9)$ \\
Entamoeba histolytica & $167(76 \cdot 6)$ & $17(16 \cdot 7)$ \\
Mixed pathogenst & & \\
Total* & & \\
\hline
\end{tabular}

NT, not tested. $\quad * \chi^{2}=99 \cdot 7186 ; \mathrm{p}<0 \cdot 0001$.

+ Forty-four diarrhoeagenic $E$. coli strains (26 EPEC, nine ETEC and nine

EAEC) were associated with polymicrobial infections. 
diarrhoeagenic $E$. coli were isolated as the sole pathogen and 44 were associated with polymicrobial infections. Other pathogens identified were rotavirus, Salmonella typhimurium, Campylobacter jejuni, Aeromonas hydrophila, Shigella spp., Cryptosporidium (oocyst) and cystic stages of Ent. histolytica (table I).

Among the diarrhoeagenic E. coli, EPEC dominated and was associated with 46 of the 218 cases as sole pathogen; EPEC were also found in seven of the 102 healthy controls. Of the isolates from the faeces of infants with diarrhoea, 43 , including 13 from mixed infections and four isolates from healthy controls, were adherent to both HEp-2 and HeLa cells. Of the 43 adherent $E$. coli isolates, 16 (12 as sole pathogen and four from mixed infections) belonged to the conventional EPEC $(\mathrm{O}: \mathrm{K})$ serogroups. The distribution of the 16 EPEC serogroups were: O128:K67 (four strains); O127:K63, O119:K69, O44:K74 (three strains each); O55:K59, O126:K71, O114:K90 (one strain each). Twelve (all as sole pathogen) of the 16 EPEC isolates showed LA and two each (all from mixed infections) showed DA or both LA and DA (table II). The remaining 27 (18 as sole pathogen and nine from mixed infections) strains were non-EPEC and were classified as EAEC resulting in overall isolation rates of $12.4 \%$ in the 218 diarrhoeal infants investigated (including mixed infections) and $1.9 \%$ in the 102 healthy controls examined. Among the 27 EAEC strains, $11(40 \cdot 7 \%)$ showed DA and $10(37 \%)$ showed LA; the other six $(22.3 \%)$ exhibited both LA and DA (table II). The distribution of the 27 EAEC strains isolated as the sole pathogen and those associated with mixed infections among DA, LA and

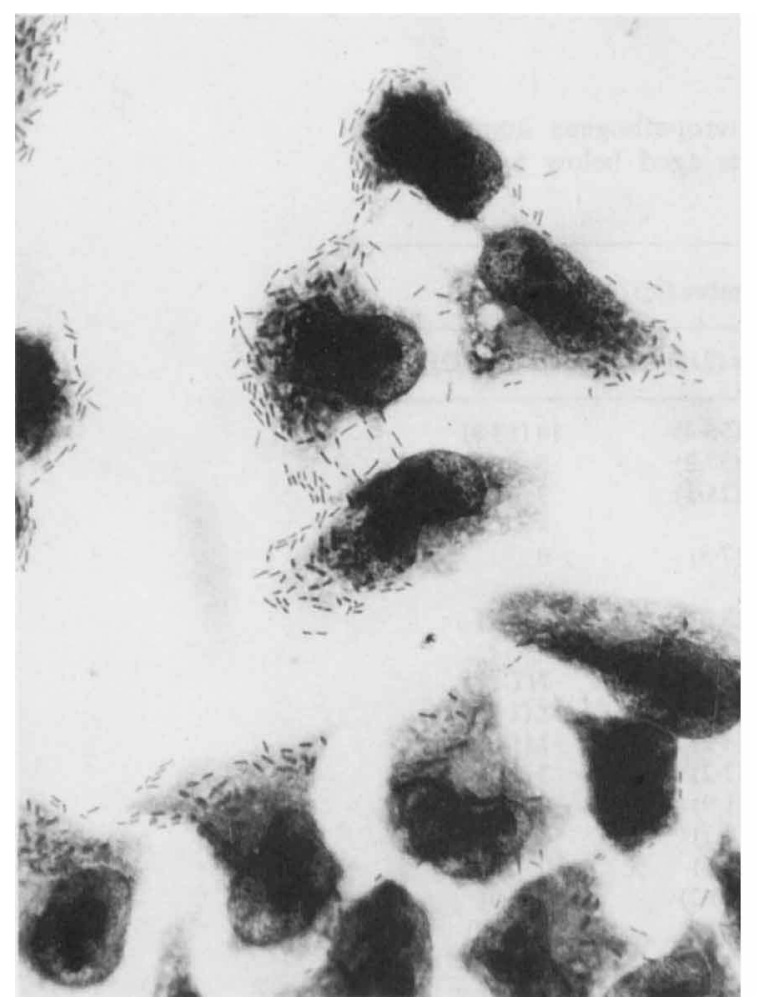

Fig. 1. Photomicrograph of cultured HeLa cells incubated with a strain of EAEC showing atypical DA $(\times 800)$.
Table II. Adherence patterns of EPEC and EAEC strains isolated from 218 infants with diarrhoea

\begin{tabular}{crr}
\hline \multirow{2}{*}{$\begin{array}{c}\text { Adherence } \\
\text { patterns }\end{array}$} & \multicolumn{2}{c}{ Number $(\%)$ of isolates of } \\
\cline { 2 - 3 } & EPEC (16) & EAEC (27) \\
\hline LA & $12(75 \cdot 0)$ & $10(37 \cdot 0)$ \\
DA & $2(12 \cdot 5)$ & $11(40 \cdot 7)$ \\
LA/DA & $2(12 \cdot 5)$ & $6(22 \cdot 3)$ \\
\hline
\end{tabular}

LA/DA were seven (sole) and four (mixed), eight and two, and three each, respectively. Four $E$. coli isolates from healthy controls exhibited DA; two belonged to the EPEC serogroups (O128:K67 and O114:K90) and two were EAEC. The DA type of adherence of a few strains of EAEC was not typical (fig. 1), but was classified as DA in this study. A photomicrograph of a representative EAEC strain exhibiting LA/DA is shown in fig. 2. The EAEC strains isolated from cases and controls were non-invasive and did not produce LT, ST or VT.

Adherence of the EAEC isolates was not inhibited by the four sugars tested or by fetuin. Screening of isolates for surface hydrophobicity by SAT revealed that $14(51.8 \%)$ were hydrophobic and belonged either to SAT group I (precipitation at $0.01-0.09 \mathrm{M}$ $\left(\mathrm{NH}_{4}\right)_{2} \mathrm{SO}_{4}$ solution) or II (precipitation at $0 \cdot 1-0.9 \mathrm{M}$ $\left(\mathrm{NH}_{4}\right)_{2} \mathrm{SO}_{4}$ solution). Furthermore, of the 14 hydrophobic isolates, eight showed mannose-sensitive haemagglutination (MSHA) with guinea-pig erythrocytes and six showed mannose-resistant haemagglutin-

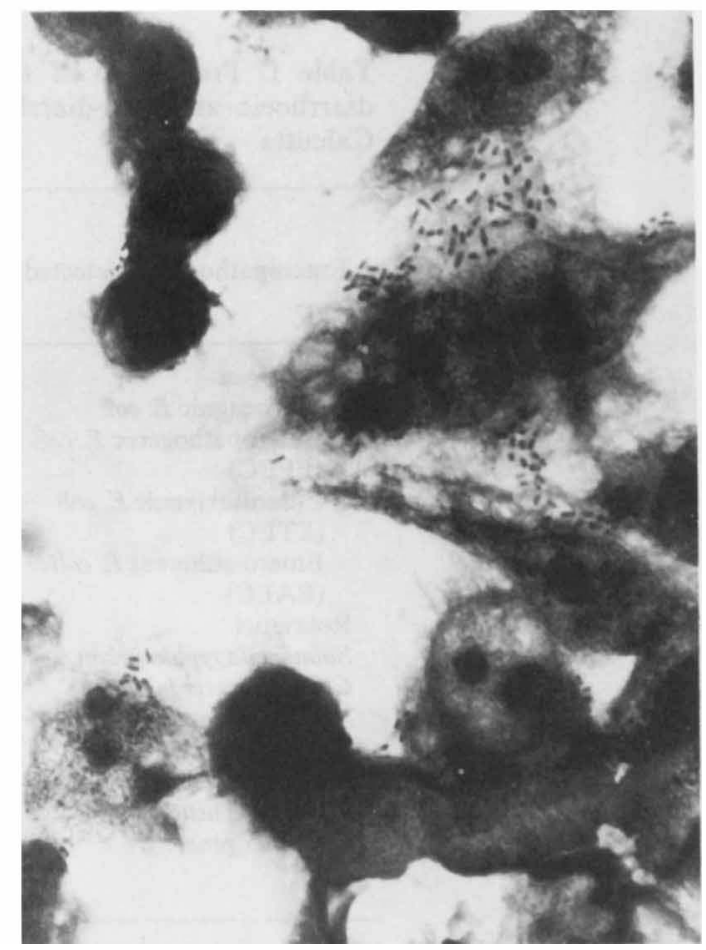

Fig. 2. Photomicrograph of cultured HeLa cells incubated with a strain of EAEC showing LA/DA $(\times 800)$. 
ation (MRHA) with chicken erythrocytes. The remaining 13 non-hydrophobic and non-haemagglutinating EAEC isolates showed all the patterns of adherence to mammalian cells, indicating that adherence was independent of the bacterial cell-surface hydrophobicity and haemagglutination properties.

\section{Discussion}

Adherence of bacteria to intestinal mucosa appears to be a pre-requisite for infection, enabling organisms to resist expulsion by peristaltic clearing mechanisms, with subsequent proliferation and colonisation of the gut. Adherence can then be followed by toxin production or invasion. Several histopathological studies in infants and animals with EPEC infections have revealed that adherence of the bacteria to the small bowel mucosa is important in the induction of diarrhoea. ${ }^{24-28}$

Mathewson et $a l^{1,6}$ claimed that certain nontoxigenic E. coli isolates, not belonging to the EPEC serogroups and exhibiting LA and DA to HEp-2, might be an important cause of travellers' and paediatric diarrhoea and termed the organisms enteroadherent $E$. coli (EAEC). Cravioto et al. ${ }^{7}$ isolated nonEPEC strains showing LA to HEp-2 cells from faeces of Mexican children without diarrhoea and Scaletsky et al..$^{29}$ observed DA to HeLa cells among non-EPEC isolates.

Mathewson et al. ${ }^{6}$ detected EAEC showing LA among $20.8 \%$ of the patients and $7.3 \%$ of the controls in Mexico. In the present study, EAEC was detected in the faeces of $12.4 \%$ of the 218 diarrhoeal infants investigated, including those with mixed infections; among the healthy controls, the isolation rate was $1.9 \%$. Only DA-EAEC was detected from healthy controls whereas strains exhibiting LA, DA, and both LA and DA were found in infants with diarrhoea. Between the two modes of adherence, recent investigations ${ }^{2,8-10}$ indicated that $E$. coli strains showing true DA were not associated with diarrhoea. Similarly, in this study, the difference in isolation rates of DA-EAEC between cases and controls was not statistically significant $\left(\chi^{2}=0.997 ; \mathrm{p}>0 \cdot 3\right)$ indicating

\section{References}

1. Mathewson JJ, Johnson PC, DuPont HL et al. A newly recognized cause of travellers' diarrhea: enteroadherent Escherichia coli. J Infect Dis 1985; 151 : 471-475.

2. Nataro, JP, Kaper JB, Robins-Browne R, Prado V, Vial PA, Levine MM. Patterns of adherence of diarrhoeagenic Escherichia coli to HEp-2 cells. Pediatr Infect Dis J 1987; 6 : 829-831.

3. Scaletsky ICA, Silva MLM, Trabulsi LR. Distinctive patterns of adherence of enteropathogenic Escherichia coli to $\mathrm{HeLa}$ cells. Infect Immun 1984; 45: 534-536.

4. Mathewson JJ, Cravioto A. HEp-2 cell adherence as an assay for virulence among diarrheagenic Escherichia coli. J Infect Dis 1989; 159: 1057-1060.

5. Vial PA, Mathewson JJ, DuPont HL, Guers L, Levine MM. that strains of E.coli exhibiting DA may not be involved in the causation of diarrhoea.

No EA-AggEC, as described by Natato et al., ${ }^{2}$ were detected in this study. The assay used for determining entero-adherence in this study was that of Cravioto $e t$ $a l^{21}$ which permits the assessment of EA-AggEC and, therefore, the inability to detect EA-AggEC is not a reflection of inadequate methodology. However, it must be emphasised that the DA exhibited by certain strains of EAEC in this study was atypical and did not correspond with the original description of even distribution of bacteria over the surface of the tissueculture cells. This atypical DA could not be classified as EA-AggEC, because of the absence of stackedbrick clumps of bacteria on the glass slides, unattached to HeLa cells, a feature which is characteristic of EAAggEC. Thus, the results suggest that EAEC exhibiting LA play an important role in causing diarrhoea in infants aged below 6 months in Calcutta; those exhibiting DA need to be evaluated more critically.

Lack of enterotoxin (LT, ST) and cytotoxin (VT/ SLT), and of the non-entero-invasive property, of the EAEC strains isolated in this study corroborates the findings of Mathewson et al ${ }^{30}$ and indicates that adherence to HEp-2 or HeLa cells, or both, is the only marker for detection of EAEC isolates. Results of hydrophobicity and haemagglutinating assays of EAEC strains suggest that adherence is independent of bacterial cell surface hydrophobicity and haemagglutination. The recent claim that plasmid-coded LA is fimbrial in nature ${ }^{31}$ has not been accepted by several workers. ${ }^{32-34}$ More detailed studies are needed to confirm the correlation between the possession of fimbriae and entero-adherence among EAEC isolates.

The duration of diarrhoea due to EAEC in the present study was 3-7 days. Practically no report is available regarding the clinical nature of the diarrhoea caused by this "newer" enteropathogen. The role of chemotherapy in the treatment of EAEC-associated diarrhoea is yet to be assessed. However, in-vitro antimicrobial susceptibility testing of the isolates in this study revealed that the EAEC are multi-resistant (unpublished observation). Further studies are needed to determine the significant of EAEC in diarrhoeal disease in man.
Comparison of two assay methods for patterns of adherence to HEp-2 cells of Escherichia coli from patients with diarrhea. J Clin Microbiol 1990; 28: 882-885.

6. Mathewson JJ, Oberhelman RA, DuPont HL, de la Cabada FJ, Garibay EV. Enteroadherent Escherichia coli as a cause of diarrhea among children in Mexico. J Clin Microbiol $1987 ; 25$ : 1917-1919.

7. Cravioto $A$, Reyes RE, Ortega R, Fernández G, Hernández R, López D. Prospective study of diarrhoeal disease in a cohort of rural Mexican children: incidence and isolated pathogens during the first two years of life. Epidemiol Infect 1988 ; 101 : 123-134.

8. Bhan MK, Raj P, Levine MM et al. Enteroaggregative Escherichia coli associated with persistent diarrhoea in a cohort of rural children in India. J Infect Dis 1989; 158: 1061-1064.

9. Gomes TAT, Blake PA, Trabulsi LR. Prevalance of Escherichia 
coli strains with localized, diffuse, and aggregative adherence to HeLa cells in infants with diarrhea and matched controls. J Clin Microbiol 1989; 27 : 266-269.

10. Kim K-H, Suh I-S, Kim JM, Kim CW, Cho Y-J. Etiology of childhood diarrhea in Korea. J Clin Microbiol 1989; 27 : 1192-1196.

11. Levine MM. Escherichia coli that cause diarrhea: enterotoxigenic, enteropathogenic, enteroinvasive, enterohemorrhagic, and enteroadherent. $J$ Infect Dis 1987; 155: $377-$ 389.

12. World Health Organization. Manual for laboratory investigation of acute enteric infections. Geneva, WHO. 1983.

13. Garcia LS, Bruckner DA, Brewer TC, Shimizu RY. Techniques for the recovery and identification of Cryptosporidium oocysts from stool specimens. J Clin Microbiol 1983; 18 : $185-190$.

14. Yolken RH, Stopa PJ. Analysis of nonspecific reactions in enzyme-linked immunosorbent assay testing for human rotavirus. J Clin Microbiol 1979; 10: 703-707.

15. Honda T, Taga S, Takeda Y, Miwatani T. Modified Elek test for detection of heat-labile enterotoxin of enterotoxigenic Escherichia coli. J Clin Microbiol 1981; 13: 1-5.

16. Svennerholm A-M, Wiklund G. Rapid GM G $_{1}$ enzyme-linked immunosorbent assay with visual reading for identification of Escherichia coli heat-labile enterotoxin. J Clin Microbiol 1983; 17: 596-600.

17. Dean AG, Ching Y-C, Williams RG, Harden LB. Test for Escherichia coli enterotoxin using infant mice: application in a study of diarrhea in Honolulu. $J$ Infect Dis $1972 ; 125$ $407-411$.

18. Konowalchuk J, Speirs JI, Stavric S. Vero response to a cytotoxin of Escherichia coli. Infect Immun 1977; 18: 775779

19. Oku Y, Uesaka Y, Hirayama T, Takeda Y. Development of a highly sensitive Bead-ELISA to detect bacterial protein toxins. Microbiol Immunol 1988; $32: 807-816$.

20. Serény B. Experimental keratoconjunctivitis shigellosa. Acta Microbiol Acad Sci Hung 1957; 4: 367-376.

21. Cravioto A, Gross RJ, Scotland SM, Rowe B. An adhesive factor found in strains of Escherichia coli belonging to the traditional infantile enteropathogenic serotypes. Curr Microbiol 1979; 3: 95-99.

22. Rozgonyi F, Szitha KR, Ljungh A, Baloda SB, Hjerten S, Wadstrom $T$. Improvement of the salt aggregation test to study bacterial cell-surface hydrophobicity. FEMS Microbiol Lett $1985 ; 30$ : 131-138.
23. Evans DJ, Evans DG, DuPont HL. Hemagglutination patterns of enterotoxigenic and enteropathogenic Escherichia coli determined with human, bovine, chicken, and guinea pig erythrocytes in the presence and absence of mannose. Infect Immun 1979; 23: 336-346.

24. Polotsky YE, Dragunskaya EM, Seliverstova VG et al. Pathogenic effect of enterotoxigenic Escherichia coli and Escherichia coli causing infantile diarrhoea. Acta Microbiol Acad Sci Hung 1977; 24 : 221-236.

25. Ulshen MH, Rollo JL. Pathogenesis of Escherichia coli gastroenteritis in man-another mechanism. New Engl J Med 1980; 302: 99-101.

26. Clausen CR, Christie DL. Chronic diarrhea in infants caused by adherent enteropathogenic Escherichia coli. J Paediatr 1982; 100: $358-361$.

27. Rothbaum R, McAdams AJ, Giannella R, Partin JC. A clinicopathologic study of enterocyte-adherent Escherichia coli, a cause of protracted diarrhea in infants. Gastroenterology $1982 ; 83: 441-454$

28. Moon HW, Whipp SC, Argenzio RA, Levine MM, Giannella RA. Attaching and effacing activities of rabbit and human enteropathogenic Escherichia coli in pig and rabbit intestines. Infect Immun 1983; 41 : 1340-1351.

29. Scaletsky ICA, Silva MLM, Toledo MRF, Davis BR, Blake PA, Trabulsi LR. Correlation between adherence to HeLa cells and serogroups, serotypes, and bioserotypes of Escherichia coli. Infect Immun 1985; 49: 528-532.

30. Mathewson JJ, Johnson PC, DuPont HL, Satterwhite TK, Winsor DK. Pathogenicity of enteroadherent Escherichia coli in adult volunteers. $J$ Infect Dis $1986 ; 154$ : 524-527.

31. Knutton S, Baldini MM, Kaper JB, McNeish AS. Role of plasmid-encoded adherence factors in adhesion of enteropathogenic Escherichia coli to HEp-2 cells. Infect Immun 1987; 55: 78-85.

32. Scotland SM, Richmond JE, Rowe B. Adhesion of enteropathogenic strains of Escherichia coli (EPEC) to HEp-2 cells is not dependent on the presence of fimbriae. FEMS Microbiol Lett 1983; 20: 191-195.

33. Levine MM, Nataro JP, Karch $\mathrm{H}$ et al. The diarrheal response of humans to some classic serotypes of enteropathogenic Escherichia coli is dependent on a plasmid encoding an enteroadhesiveness factor. $J$ Infect Dis $1985 ; 152$ : 550-559.

34. Andrade JRC, Santa Rosa MR. Investigation on an adhesive property (localised adherence) characteristic of classical enteropathogenic serotypes of Escherichia coli. Revista de Microbiologia 1986; 17: 116-125. 